\title{
A Bibliometric Analysis of Research Trends of Acupuncture Therapy in the Treatment of Migraine from 2000 to 2020
}

\author{
Tingting Zhaol,* \\ Jing Guol,* \\ Yafang Song ${ }^{2}$ \\ Hao Chen (D) ${ }^{2}$ \\ Mengzhu Sun' \\ Lu Chen ${ }^{3}$ \\ Hao Geng ${ }^{3}$ \\ Lixia Pei ${ }^{3}$ \\ Jianhua Sun (1) $^{3}$
}

'Affiliated Hospital of Nanjing University of Chinese Medicine, Nanjing, Jiangsu Province, People's Republic of China; ${ }^{2}$ Nanjing University of Chinese Medicine, Nanjing, Jiangsu Province, People's Republic of China; ${ }^{3}$ jiangsu Province Hospital of Chinese Medicine, Nanjing, Jiangsu Province, People's Republic of China

*These authors contributed equally to this work
Correspondence: Jianhua Sun; Lixia Pei Department of Acupuncture

Rehabilitation, The Affiliated Hospital of Nanjing University of Chinese Medicine, Hanzhong Road, Qinhuai District, Nanjing, Jiangsu Province, People's

Republic of China

Email377201634@qq.com;

II80I758@qq.com
Background: Migraine is the second-leading cause of disability worldwide. It is often characterized by attacks of severe, mostly unilateral, pulsating headache associated with symptoms such as photophobia, phonophobia, nausea, vomiting, and cutaneous allodynia. Acupuncture therapy has been used worldwide for the treatment of migraine. However, no visual bibliometric analysis has been conducted on the effects of acupuncture on migraine over the past 20 years. Therefore, this study aimed to explore the current status and trends on the use of acupuncture in the treatment of migraine from 2000 to 2020.

Purpose: The objective of this study is to identify the current status and emerging trends of the global use of acupuncture on migraine from 2000 to 2020 using CiteSpace and VOSviewer.

Methods: Web of Science databases were searched for publications related to acupuncture therapy for treating migraine between 2000 and 2020. CiteSpace and VOSviewer were used to analyze the number of publications per year, countries, institutions, authors, journals, references, and keywords.

Results: A total of 572 publications were included in the final analysis. The total number of publications has continued to increase with some fluctuations over the past 20 years. The most productive country and institution in this field were the USA, and Chengdu University of Traditional Chinese Medicine, respectively. The most active and cited authors were Liang FR and Linde K, respectively. Cephalalgia was the most productive, cited, and co-cited journal. The Linde K (2005) had the highest co-citation, citation number and centrality. The keywords "migraine" ranked first in frequency. The common type of migraine (tension-type headache), research method (randomized controlled trial, multicenter, double-blind), acupuncture's role (prophylactic, quality of life, pain), and evaluation (meta-analysis, systematic review) were the hotspots and frontier trends of acupuncture therapy on migraine between 2000 and 2020.

Conclusion: The present study examined the research-related trend in acupuncture therapy on migraine using bibliometric methods and identified the statement and research frontiers over the past two decades. This may help researchers to identify potential hotspots and new directions for future research in this field.

Keywords: acupuncture, migraine, bibliometric analysis, CiteSpace, VOSviewer, network

\section{Introduction}

Migraine is characterized by attacks of throbbing, often unilateral, severe and pulsating headache, and associated with symptoms such as phonophobia, photophobia, vomiting, nausea, and cutaneous allodynia. ${ }^{1-3}$ As the second leading cause of disability 
worldwide, ${ }^{4,5}$ migraine significantly contribute to individual and societal burdens due to severe pain and environmental sensitivities. ${ }^{6-8}$ Epidemiological studies have shown a higher prevalence of migraine in recent years. ${ }^{5,9,10}$ The pharmacological treatment of migraine includes prophylaxis aimed at reducing the frequency, duration, and severity of migraine attacks, and acute therapy used to relieve pain at the acute stage. ${ }^{11-13}$ Several drugs, such as propranolol, metoprolol, flunarizine, valproic acid, topiramate, and divalproex sodium, have been shown to reduce the frequency of migraine attacks. $^{14-16}$ However, an obvious risk of adverse effects associated with oral administration is reported, such as weight gain, fatigue, sleep disorders, liver damage, metabolic disorders, and gastrointestinal reactions. ${ }^{17,18}$

Acupuncture therapy is a widely used treatment to effectively manage migraines, with potential effect. ${ }^{19-21}$ Numerous studies have shown beneficial effects of acupuncture, including pain relief, ${ }^{22}$ improved quality of life $(\mathrm{QoL}){ }^{23}$ reduce anxiety, $^{24}$ reduce depression, ${ }^{25}$ and improved brain function. ${ }^{26}$ Evidence-based multicenter randomized controlled trials (RCT) have suggested that real acupuncture (TA) greatly reduces pain reduction compared with sham acupuncture (SA) and improves the QoL and emotional function. ${ }^{8,22}$ Acupuncture was reported to modulate abnormal brainstem activity in patients with migraine by $\mathrm{Li}$ et al, indicating that TA and SA modulate different effects of low-frequency fluctuations of the rostral ventromedial medulla and trigeminocervical complex. ${ }^{27}$

Bibliometrics refers to a quantitative tool for analysis of published scientific literature. The relationship between a research statement and emerging research frontiers is identified through co-occurrence, citation, and cocitation. $^{28}$ Recently, several global bibliometric analyses of general status and research trends in acupuncture therapy for pain, cancer, low back pain, insomnia have been conducted using CiteSpace and VOSviewer. ${ }^{29-32}$ However, to the best of our knowledge, a bibliometric analysis of the use of acupuncture for migraine has not yet been performed.

Therefore, the objective of the present study is to evaluate important research trends of acupuncture on migraine, based on the co-occurrence network of countries, institutions, authors, journals, references, and keywords over the past 20 years through bibliometric analysis. The global use of acupuncture on migraine will be explored using CiteSpace and VOSviewer.

\section{Methods}

Publications were obtained from the Web of Science (WoS) database via the Nanjing University of Chinese Medicine Library website (Science Citation Index Expanded (SCIExpanded), Social Sciences Citation Index (SSCI), Arts \& Humanities Citation Index (A\&HCI), Conference Proceedings Citation Index-Science (CPCI-S), Conference Proceedings Citation Index-Social Sciences \& Humanities (CPCI-SSH), Book Citation Index-Science (BKCI-S), Book Citation Index Social Science \& Humanities (BKCI$\mathrm{SSH}$ ), and Emerging Sources Citation Index (ESCI)). The data search strategy included the topic "migraine" and "acupuncture therapy", and the publication period of the literature ranged from January 1, 2000, to December 31, 2020. The search was not restricted to the category, language or document type. Two authors independently searched the references. Any differences were resolved by LX Pei and JH Sun, and a total of 572 references were identified (Table 1). We analyzed the document using CiteSpace software, and the results showed that there was no duplicate publication.

Analysis Tool

The intrinsic function of the WoS database was used to analyse publication features, including publication outputs, countries, institutions, authors, and journals. CiteSpace 5.7. $\mathrm{R} 5$ was used to explore the co-occurrence relationships of countries, institutions, authors and keywords, and the co-

Table I Search Queries

\begin{tabular}{|l|l|l|}
\hline Set & Result & \multicolumn{1}{c|}{ Search Query } \\
\hline$\#$ I & 27,45 I & $\begin{array}{l}\text { Acupuncture Therapy OR Acupuncture Treatment } \\
\text { OR Pharmacoacupuncture Treatment OR } \\
\text { Acupotomy OR electroacupuncture OR electro- } \\
\text { acupuncture OR Acupuncture OR body } \\
\text { acupuncture OR Manual Acupuncture OR auricular } \\
\text { OR Auricular Acupuncture OR auricular needle OR } \\
\text { acupuncture point OR Ear Acupuncture OR Warm } \\
\text { Acupuncture OR Moxibustion OR Moxabustion OR } \\
\text { acupoint injection OR catgut embedding OR catgut } \\
\text { implantation at acupoint OR embedding thread }\end{array}$ \\
\hline$\# 2$ & 39,507 & $\begin{array}{l}\text { Migraine Disorders OR migraine OR Migraine } \\
\text { Headache OR Migraine Disorder OR Acute } \\
\text { Confusional Migraine OR Status Migrainosus OR } \\
\text { Hemicrania Migraine OR Migraine Variant OR Sick } \\
\text { Headache OR Abdominal Migraine OR Cervical } \\
\text { Migraine Syndrome }\end{array}$ \\
\hline \#3 572 & \begin{tabular}{l} 
\#I AND \#2 \\
\hline
\end{tabular} \\
\hline
\end{tabular}


citation relationships of authors, journals and references. All documents were downloaded as a.txt and windows UTF-8 file, and imported into CiteSpace and VOSviewer, respectively.

CiteSpace, an excellent scientific econometric analysis software invented by professor Chaomei Chen, and a professional tool used to analyze research literature. ${ }^{33,34}$ The parameters of CiteSpace were set as follows: (1) timespan (2000-2020), years per slice; (2) one node type was selected at a time; (3) selection criteria top 50 objects; (4) pathfinder and pruning sliced networks; (5) look back years $(\mathrm{LBY}=8)$; $(6)$ link retaining factor $(\mathrm{LRF}=2)$; (7) percentage of nodes to label $(\mathrm{PNL}=5 \%)$; (8) maximum links per node (MLPN $=10)$; (9) e for top $\mathrm{N}(\mathrm{e}=2)$. The VOSviewer software was invented by van EckNJ, who worked at Leiden University. ${ }^{35,36}$ The cooccurrence knowledge maps of countries, institutions, authors, journals, keywords, and citation networks of countries, institutions, journals, references were analyzed.

A node represents an element such as country, institution, author, journal, reference, and keyword. A larger width of links between nodes represents stronger cooperation, while a larger size of the node indicates a high number of publications. Nodes with high centrality mean a turning point or pivotal point related to this field, ${ }^{37,38}$ and is represented by purple color. ${ }^{39}$

\section{Results}

\section{Annual Publication and Trends}

The number of publications in WoS on acupuncture in migraine has increased from 2000 to 2020 , even though there have been some fluctuations (Figure 1A). The model fitting curves of growth was used to predict the publications trend (Figure 1B), and the rate of publication outputs was predicted to increase in the future.

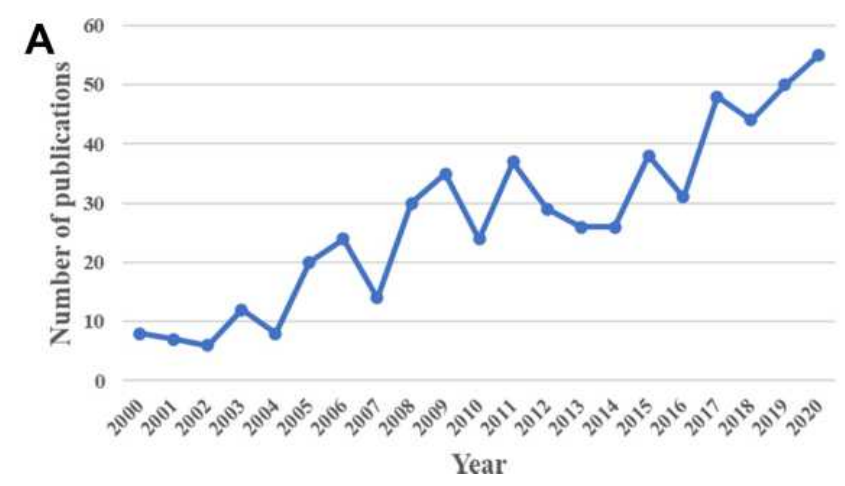

\section{Analysis of Document Type}

Eight document types were identified in 572 documents (Table 2). Articles (377) were the most frequently used document type, accounting for $65.91 \%$ of the total publications, and they were followed by reviews (113, 19.76\%). "Acupuncture for patients with migraine-A randomized controlled trial" was the most cited article, with 386 citations. $^{3}$ The most cited review was "Revised standards for reporting interventions in clinical trials of acupuncture (STRICTA): extending the consort statement" ${ }^{40}$

\section{Distribution of Countries}

The co-occurrence analysis of countries and regions in this field was performed using CiteSpace. The merged network comprised 44 nodes and 93 links (Figure 2A), indicating that 44 countries participated in acupuncture research on migraine. As a result, the USA (160) had the most publications, followed by China (148), Germany (103), England (49), and Italy (35). Considering the country centrality, the USA (0.36) ranked first among the countries, followed by Germany (0.13), Switzerland (0.13), China (0.10), and England (0.08). In addition, the overlay, density, and citation visualization of countries were constructed using VOSviewer (Figure 2B-D). Germany had the highest number of citations (3675), followed by the USA (3552), England (2544), China (2190), and Switzerland (1639; Table 3).

\section{Distribution of Institution}

CiteSpace was used to estimate the 405 institutions that made significant contributions in this field. Among the 405 nodes and 617 links, Chengdu University of Traditional Chinese Medicine (40) ranked first for publications, followed by Harvard University (33), and Technical University Munich (30). With respect to centrality, the top 3 institutions were

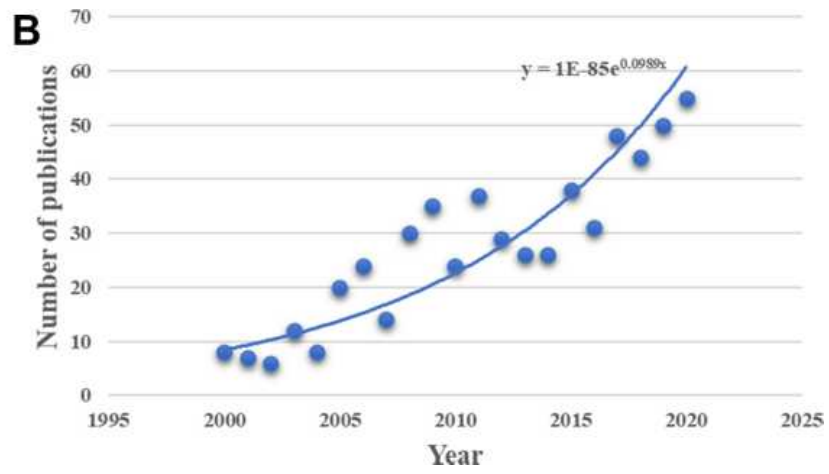

Figure I (A). The annual number of publications related to acupuncture on migraine. (B). Model fitting curves of growth trends and prediction of publications numbers in the future. 
Table 2 Document Types Related to Acupuncture on Migraine

\begin{tabular}{|l|c|c|}
\hline Ranking & Type & Counts (\%) \\
\hline 1 & Article & $377(65.91 \%)$ \\
2 & Review & $113(19.76 \%)$ \\
3 & Editorial Material & $35(6.11 \%)$ \\
4 & Proceedings Paper & $8(1.40 \%)$ \\
5 & Meeting Abstract & $20(3.50 \%)$ \\
6 & Letter & $10(1.75 \%)$ \\
7 & News Item & $6(1.05 \%)$ \\
8 & Correction & $3(0.52 \%)$ \\
\hline
\end{tabular}

Heidelberg University (0.12), Technical University Munich (0.10), and Ruhr University Bochum (0.09; Figure 3A; Table 4). Meanwhile, the overlay visualization, minimum of 6 collaborative documents, and citations of institutions were analyzed by VOSviewer (Figure 3B-D). Technical University Munich had the highest citations (2195), followed by Charite University Medicine Berlin (1129) and University Zurich Hospital (1099).

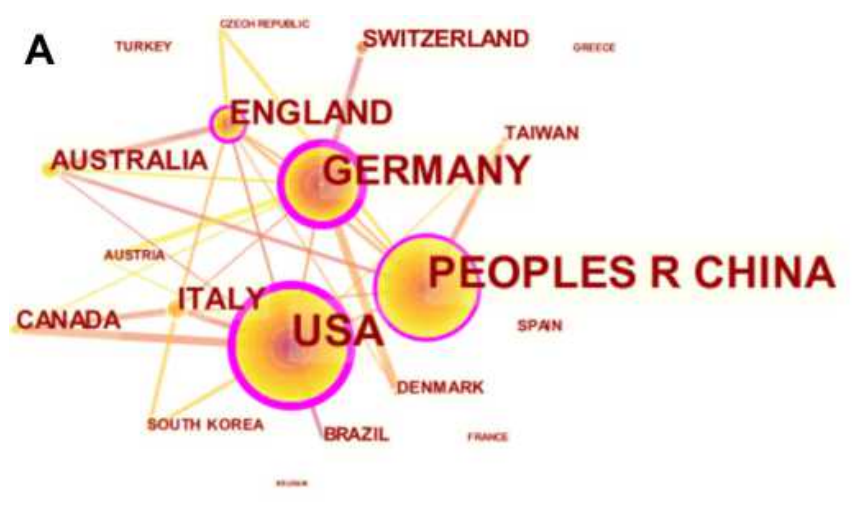

C

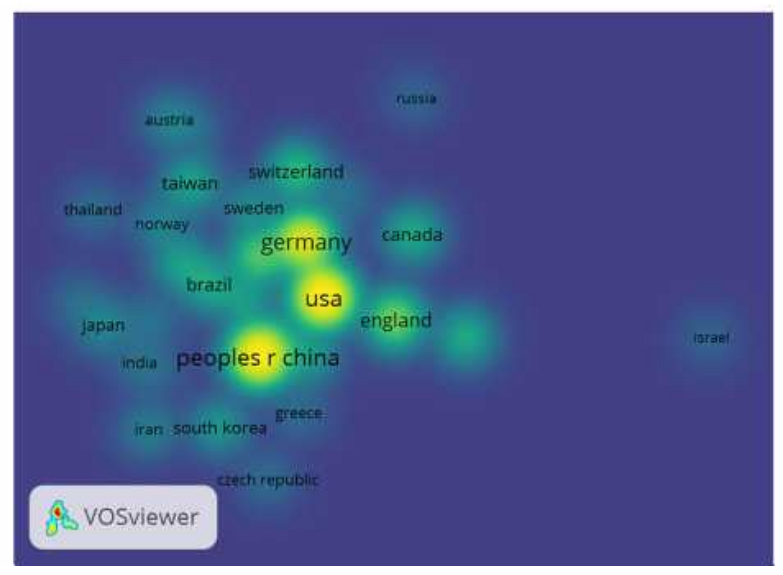

\section{Analysis of Author}

CiteSpace was used to analyze the co-occurrence of authors and co-cited authors, while the overlay visualization and collaboration network of authors were performed by VOSviewer. A total of 556 published authors on acupuncture for migraine were analyzed. Table 5 lists the top 3 productive authors, including Liang FR (29), Linde $\mathrm{K}$ (28), and $\mathrm{Li} \mathrm{Y}$ (18). The top 3 authors in terms of centrality were Claudia M Witt (0.03), Liang FR (0.02), and Lei L (0.02; Figure 4A). The top 10 co-cited authors are shown in Table 5, with Linde K (260) ranking first, followed by Diener HC (160), and Melchart D (142). HESSE J had the most centrality $(0.16)$, followed by Birch $S(0.10)$, and Macherson H (0.09) (Table 6; Figure 4B-D).

\section{Analysis of Journals}

The VOSviewer was used to analyze the top 10 acupuncture journals on migraine as shown in Table 7. Cephalalgia $(31,5.50 \%)$ was the most productive journal, followed by

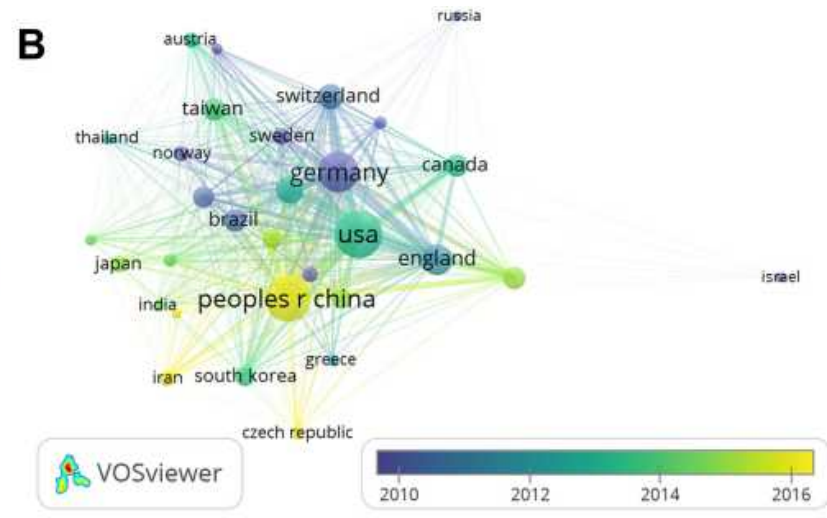

D

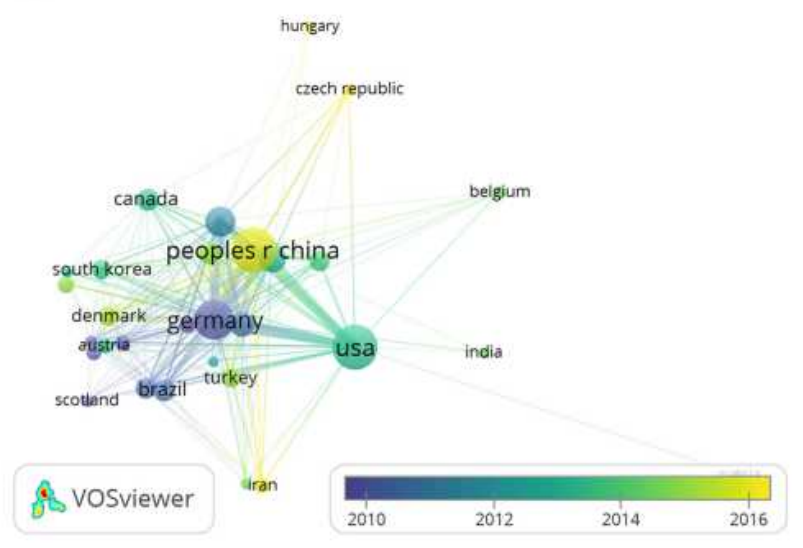

Figure 2 (A) The collaboration network of countries researching acupuncture on migraine. (B) The overlay visualization network of countries related to acupuncture on migraine. (C) The density visualization of countries related to acupuncture on migraine. (D) The overlay visualization network of cited countries related to acupuncture on migraine. 
Table 3 Top 10 Publications, Centrality and Citations of Countries Related to Acupuncture on Migraine

\begin{tabular}{|l|c|c|c|c|c|c|}
\hline Rank & Publications & Countries & Centrality & Countries & Citations & Countries \\
\hline 1 & 160 & USA & 0.36 & USA & 3675 & Germany \\
2 & 148 & China & 0.13 & Germany & 3552 & USA \\
3 & 103 & Germany & 0.13 & Switzerland & 2544 & England \\
4 & 49 & England & 0.10 & China & 2190 & China \\
5 & 36 & Italy & 0.08 & England & 1639 & Switzerland \\
6 & 27 & Switzerland & 0.08 & Denmark & 1054 & Italy \\
7 & 20 & Australia & 0.07 & Canada & 62 I & Canada \\
8 & 20 & Canada & 0.07 & Sweden & 390 & Denmark \\
9 & 19 & Brazil & 0.06 & Iran & 297 & Sweden \\
10 & 17 & Taiwan & 0.05 & Italy & 292 & Australia \\
\hline
\end{tabular}

Headache (28, 4.96\%), and Acupuncture In Medicine (22, $3.90 \%$; Figure $5 \mathrm{~A}$ and B). Cephalalgia ranked first in the number of citations (672), followed by Pain (666), and Headache (665; Table 7; Figure 5C). Co-citation was determined using CiteSpace. In terms of frequency, Cephalalgia (326) ranked first, followed by Headache
(314), Pain (272), and JAMA-Journal of the American Medical Association (260). The journal of Acupuncture Electro-Therapeutics Research ranked (0.13) first in centrality, followed by Brain research (0.11), and Journal of Neurology Neurosurgery and Psychiatry (0.10; Table 8; Figure 5D).
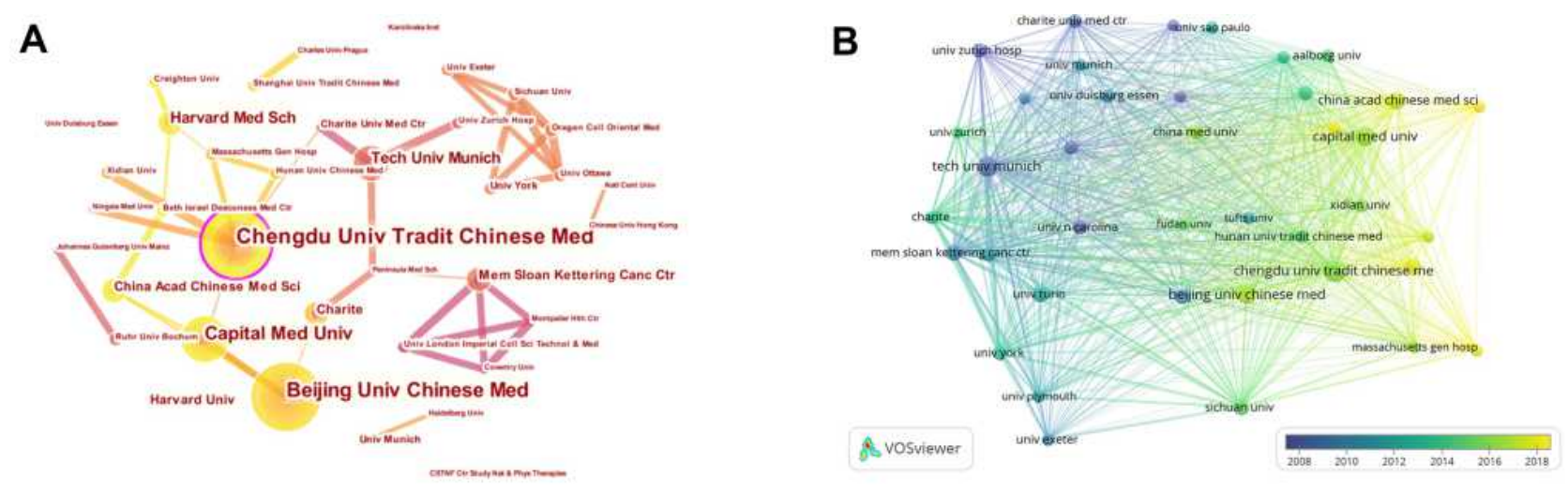

C
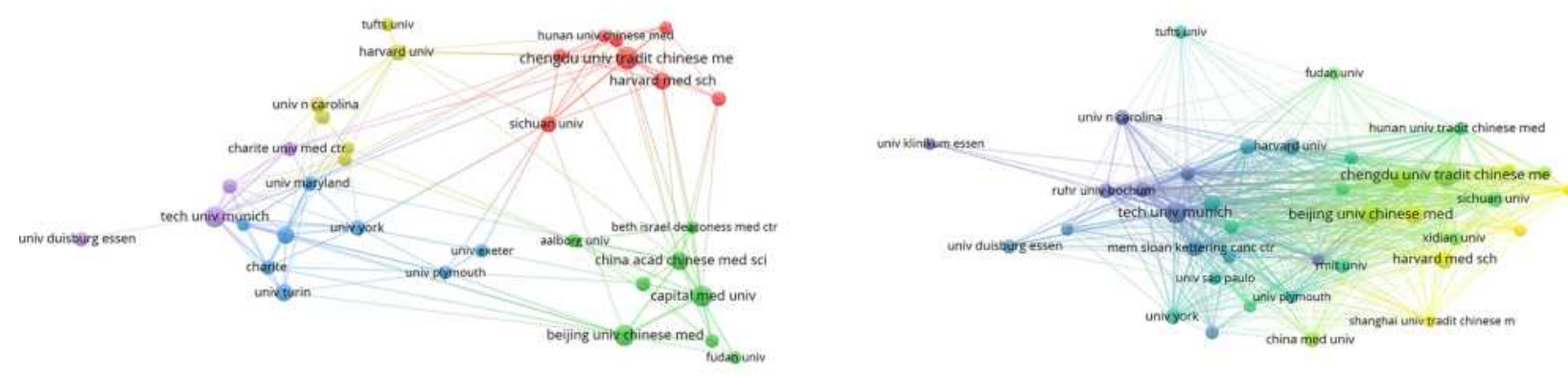

As vosviewer

Do vosviewer

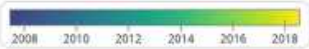

Figure 3 (A) The collaboration of institutions related to acupuncture on migraine. (B) The overlay visualization network of institutions related to acupuncture on migraine. (C) The collaboration between institutions with more than 6 publications. (D) The overlay visualization network of cited institutions related to acupuncture on migraine. 
Table 4 Top 10 Publications, Centrality, and Citations of Institutions Related to Acupuncture on Migraine

\begin{tabular}{|c|c|c|c|c|c|c|}
\hline Rank & Counts & Institution & Centrality & Institutions & Citations & Institution \\
\hline I & 40 & Chengdu Univ Tradit Chinese Med & 0.12 & Heidelberg Univ & 2195 & Tech Univ Munich \\
\hline 2 & 33 & Harvard Univ & 0.10 & Tech Univ Munich & 1129 & Charite Univ Med Berlin \\
\hline 3 & 30 & Tech Univ Munich & 0.09 & Ruhr Univ Bochum & 1099 & Univ Zurich Hosp \\
\hline 4 & 27 & Beijing Univ Chinese Med & 0.08 & Chengdu Univ Tradit Chinese Med & 1064 & Mem Sloan Kettering Canc Ctr \\
\hline 5 & 26 & Capital Med Univ & 0.07 & Harvard Univ & 885 & Univ York \\
\hline 6 & 25 & Charite Univ Med Berlin & 0.06 & Mem Sloan Kettering Canc Ctr & 717 & Sichuan Univ \\
\hline 7 & 25 & Free Univ Berlin & 0.05 & Duke Univ & 701 & Charite \\
\hline 8 & 25 & Humboldt Univ Berlin & 0.04 & Beijing Univ Chinese Med & 700 & Univ Maryland \\
\hline 9 & 25 & Univ Duisburg Essen & 0.04 & Charite Univ Med Berlin & 670 & Univ Plymouth \\
\hline 10 & 19 & Univ Zurich & 0.03 & Aalborg Univ & 640 & Univ Exeter \\
\hline
\end{tabular}

Table 5 Top 10 Publications and Centrality of Authors Related to Acupuncture on Migraine

\begin{tabular}{|l|c|c|c|c|c|}
\hline Rank & Publications & Author & Rank & Centrality & Author \\
\hline I & 29 & Liang FR & 1 & 0.03 & Witt CM \\
2 & 28 & Linde K & 2 & 0.02 & Liang FR \\
3 & 18 & Li Y & 3 & 0.02 & Lei L \\
4 & 18 & Zheng H & 4 & 0.01 & Linde K \\
5 & 17 & Diener HC & 5 & 0.01 & Allais G \\
6 & 17 & Wang LP & 6 & 0.01 & Brinkhaus B \\
7 & 15 & Allais G & 7 & 0.01 & Vickers A J \\
8 & 15 & Mel Chart D & 8 & 0.01 & Macpherson H \\
9 & 14 & Witt CM & 9 & 0.0 I & Sun GJ \\
10 & 13 & Brinkhaus B & 10 & 0.00 & Zheng H \\
\hline
\end{tabular}

\section{Analysis of References}

CiteSpace was used to analyze the co-citation count, centrality, and cluster. The top 10 cited references are shown in Table 9 and Figure 6. The article published by Linde $\mathrm{K}$ in 2005 had the highest co-citation counts (91), ${ }^{3}$ followed by Diener HC, 2006 (79), and Li Y, 2012 (53). With respect to centrality of co-cited references, Linde K $(2005 ; 0.85)$ ranked first, with the article, elucidating acupuncture and routine care in migraine patients had significant improvement of symptoms compared with routine care. ${ }^{41}$ Besides, articles published by Diener HC (2006; 0.70), and Allais G (2002; 0.67) also attracted significant attention in co-citation of acupuncture for migraine (Figure 6A).

Noun phrases were obtained from the cited reference to obtain clusters, which reflected the research patterns and frontier topics in networks. The top 5 clusters were "manual acupuncture", "acupuncture study", "chronic headache", "chronic headache disorders", and "consort statement" (Figure 6B and C). "Chronic headache" was an earlier cluster, while "manual acupuncture" was the cluster in the last few years. In terms of citations, Linde K, 2005 (386) was the most cited article in this field, followed by MacPherson, 2010 (353) published in PLoS Medicine, and Dowson, 2008 (351; Figure 6D).

\section{Analysis of Keywords}

The keywords "migraine", "headache", "tension-type headache", "chronic pain", "analgesia”, "pain”, "acupuncture", "electroacupuncture", "randomized controlled trial", "double-blind", "prophylaxi”, "placebo", “complementary medicine", "management”, "meta-analysis", "QoL”, “systematic review", and "fmri" were popular keywords over the past two decades. The top 3 clusters were "prevention", "electroacupuncture", and "functional magnetic resonance imaging" (Table 10; Figures 7A-D and 8A). The burst keywords showed increasing attention on research in acupuncture on migraine in recent years, which is the main indicator for frontier trends in this field. ${ }^{42}$ The keywords "management", "meta-analysis", "QoL", and "systematic review" had the strongest keyword bursts in the recent four years (Figure 8B). 

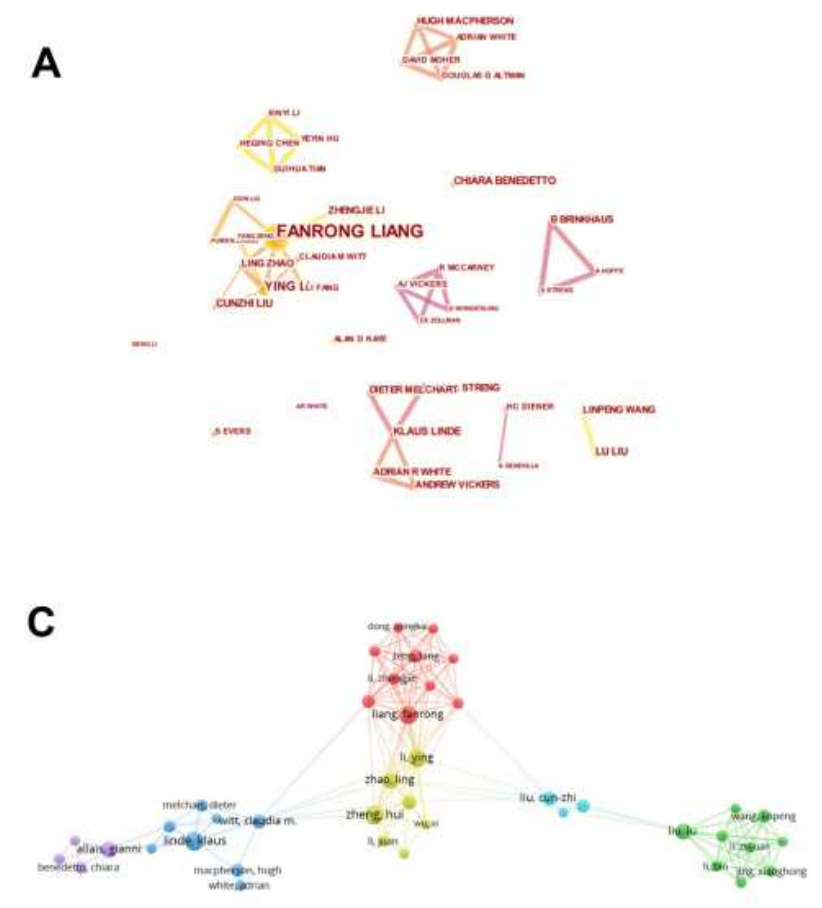

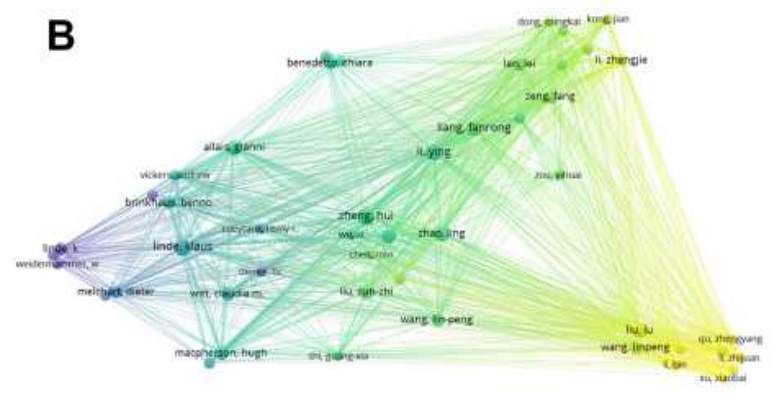

A voswiemer

D

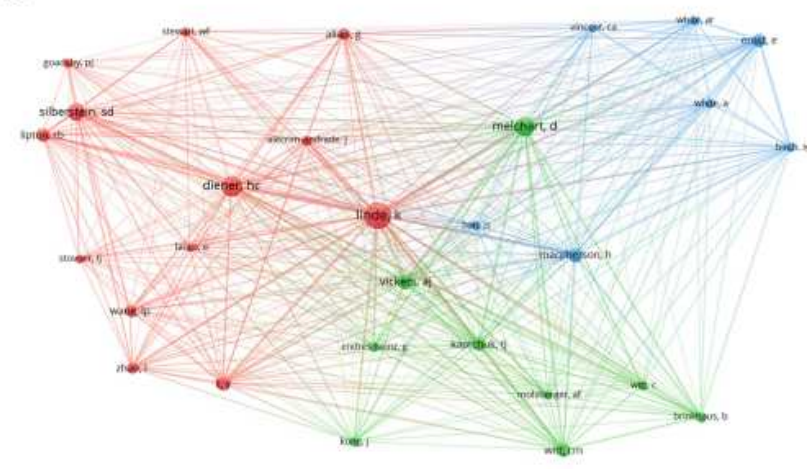

As voswewer

Figure 4 (A) The collaboration network of authors related to acupuncture on migraine. (B) The overlay visualization network of authors related to acupuncture on migraine. (c) The network of co-authorship between authors. (D) The collaboration network of co-cited authors related to acupuncture on migraine.

\section{Discussion}

\section{Research Trends in Acupuncture on Migraine from 2000 to 2020}

The increasing number of publications in acupuncture on migraine show that research in this field is gaining significant attention. Besides, the annual number of publications is

Table 6 Top 10 Counts and Centrality of Co-Cited Authors Related to Acupuncture on Migraine

\begin{tabular}{|l|c|c|c|c|}
\hline Rank & Counts & Author & Centrality & Author \\
\hline $\mathrm{I}$ & 260 & Linde K & 0.16 & Hesse J \\
2 & 165 & Diener HC & 0.10 & Birch S \\
3 & 142 & Mel Chart D & 0.09 & Macpherson H \\
4 & 131 & Silberatein SD & 0.08 & Mel Chart D \\
5 & 106 & Vickers AJ & 0.08 & Lipton RB \\
6 & 86 & Lipton RB & 0.07 & Kaptchuk TJ \\
7 & 77 & Li Y & 0.07 & Han JS \\
8 & 77 & Macpherson H & 0.07 & Silberatein SD \\
9 & 76 & Allais G & 0.07 & Diener HC \\
10 & 64 & Witt CM & 0.06 & Allais G \\
\hline
\end{tabular}

predicted to markedly increase in the future. Acupuncture, as one of the most common complementary and alternative therapy for migraine, is widely used for managing migraine in many countries. ${ }^{1,43,44}$ Countries that greatly contributed to acupuncture on migraine research are the USA, China, Germany, England, and Italy. Besides, the USA, Germany, and Switzerland have maintained a high degree of cooperation with other countries. In this study, considering the number of publications, centrality, and citations, the USA was found to play a key role in this field. Additionally, China, Turkey, Czech Republic, and Iran are other countries shown to play a significant role in acupuncture on migraine research over the last few years.

The analysis of collaborating institutions can help identify the most productive groups on a topic. ${ }^{31}$ Chengdu University of Traditional Chinese Medicine had the highest number of publications, an indication that the institution made significant contributions to acupuncture on migraine research. Technical University Munich published 30 articles, cited at 2195 , and with a centrality of 0.12 , suggesting that it also played an important role in this field. Furthermore, the 
Table 7 Top 10 Publications, Citation Journals Related to Acupuncture on Migraine

\begin{tabular}{|l|c|c|c|c|}
\hline Rank & Publications & Journal & Citation & Journal \\
\hline 1 & 31 & Cephalalgia & 672 & Cephalalgia \\
2 & 28 & Headache & 666 & Pain \\
3 & 22 & Acupuncture Med & 665 & Headache \\
4 & 21 & J Altern Complem Med & 615 & J Altern Complem Med \\
5 & 16 & Evid-Based Compl Alt & 485 & Cochrane Db Syst Rev \\
6 & 16 & Trails & 379 & Acupuncture Med \\
7 & 13 & Neurol Sci & 338 & BMJ-Brit Med J \\
8 & 10 & Chin J Integr Med & 235 & Complement Ther Med \\
9 & 10 & Deutsche Zeitschrift Fur Akupunktur & 223 & Trails \\
10 & 10 & Medicine & 205 & Evid-Based Compl Alt \\
\hline
\end{tabular}

overlay visualization revealed that Chengdu University of Traditional Chinese Medicine, Beijing University Chinese Medicine, Capital Medicine University, and Harvard Medical School made significant contributions to the field in recent years.



C

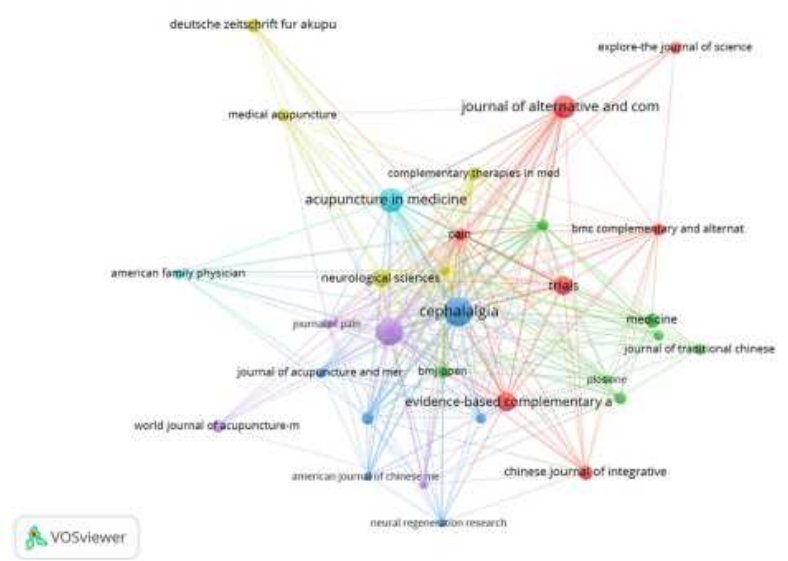

The network analysis of publications, co-authorship and co-citation of authors identifies influential authors and potential collaborations related to acupuncture on migraine. $^{31}$ Liang FR, Linde $\mathrm{K}$, Li $\mathrm{Y}$, Zheng $\mathrm{H}$, and Diener HC were important authors of publications related

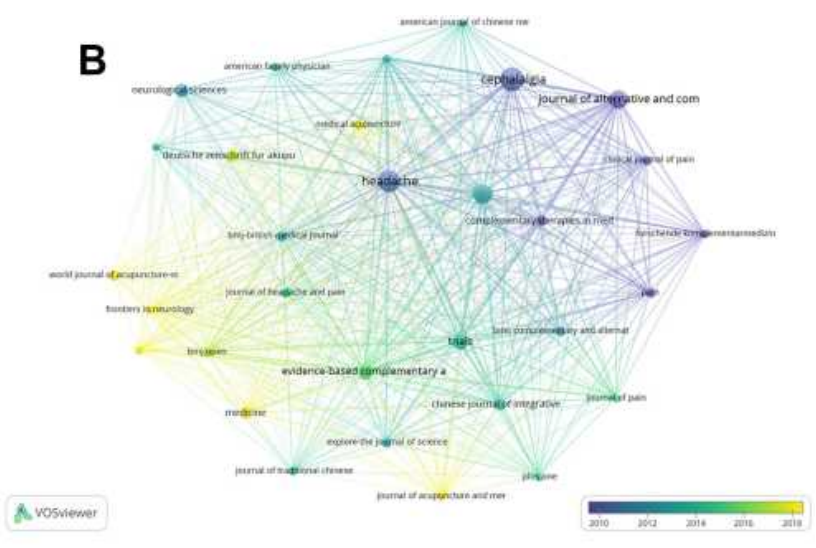

D

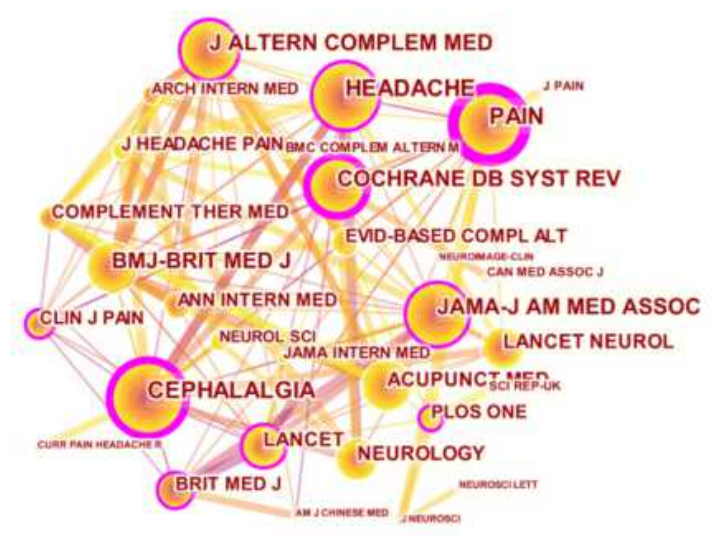

Figure 5 (A) The visualization network of journals in acupuncture for migraine. (B) The overlay network of journals in acupuncture on migraine. (C). The visualization network of cited journals in acupuncture on migraine. (D) The co-citation network of journals in acupuncture on migraine. 
Table 8 Top 10 Co-Citation Journals Related to Acupuncture on Migraine

\begin{tabular}{|l|c|c|c|c|}
\hline Rank & Frequency & Journal & Centrality & Journal \\
\hline 1 & 326 & Cephalalgia & 0.13 & Acupuncture Electro \\
2 & 314 & Headache & 0.11 & Brain Res \\
3 & 272 & Pain & 0.10 & J Neurol Neurosur Ps \\
4 & 260 & JAMA-J Am Med Assoc & 0.10 & Acupuncture Clin Pra \\
5 & 205 & Cochrane Db Syst Rev & 0.09 & Brain \\
6 & 191 & J Altern Complem Med & 0.09 & J Tradit Chin Med \\
7 & 189 & BMJ-Brit Med J & 0.08 & Clin J Pain \\
8 & 183 & Neurology & 0.08 & Anesth Analg \\
9 & 167 & Lancet Neurol & 0.07 & Am J Chinese Med \\
10 & 165 & Lancet & 0.07 & J Acupunct Meridian \\
\hline
\end{tabular}

Table 9 Top 10 References Related to Acupuncture on Migraine

\begin{tabular}{|c|c|c|c|c|c|c|}
\hline Rank & $\begin{array}{l}\text { Co-Citation } \\
\text { Counts }\end{array}$ & $\begin{array}{c}\text { Reference } \\
\text { (Publication Year) }\end{array}$ & Centrality & $\begin{array}{c}\text { Reference } \\
\text { (Publication Year) }\end{array}$ & $\begin{array}{l}\text { Citation } \\
\text { Counts }\end{array}$ & $\begin{array}{c}\text { Reference } \\
\text { (Publication Year) }\end{array}$ \\
\hline I & 91 & Linde K, 2005 & 0.85 & Linde K, 2005 & 386 & Linde K, 2005 \\
\hline 2 & 79 & Diener HC, 2006 & 0.70 & Diener HC, 2006 & 353 & $\begin{array}{c}\text { Macpherson, } 2010 \text { (PLoS } \\
\text { Medicine) }\end{array}$ \\
\hline 3 & 53 & $\mathrm{Li} \mathrm{Y,} 2012$ & 0.67 & Allais G, 2002 & 351 & Dowson,2008 \\
\hline 4 & 50 & Linde K, 2009 & 0.42 & Wang LP, 20II & 335 & Linde K, 2007 \\
\hline 5 & 41 & Bes A, 2013 & 0.36 & Melchart D, 2005 & 236 & Diener HC, 2006 \\
\hline 6 & 39 & Wang LP, 20II & 0.33 & Li Y, 2012 & 220 & Melchart D, 2005 \\
\hline 7 & 38 & Zhao L, 2017 & 0.27 & Zhao L, 2017 & 212 & $\begin{array}{c}\text { Linde K, } 2009 \text { (Cochrane Db } \\
\text { Syst Rev) }\end{array}$ \\
\hline 8 & 37 & Vickers AJ, 2012 & 0.27 & Melchart D, 1999 & 163 & Moffet, 2009 \\
\hline 9 & 37 & Linde K, 2016 & 0.25 & Linde K, 2016 & 157 & Vickers AJ, 2004 \\
\hline 10 & 37 & Melchart D, 2005 & 0.23 & Ramsay DJ, 1998 & 143 & White, AR, 200I \\
\hline
\end{tabular}

to acupuncture on migraine. Liang, F, is the main researcher working at Chengdu University of Traditional Chinese Medicine devoted to research on acupuncture for migraine over the last few years. A study performed by Liang, F research showed the regional homogeneity change in migraine without aura patients using fMRI. ${ }^{45}$ Linde $\mathrm{K}$ from the Technical University Munich had the highest number of co-citations. Moreover, Liu L, Li B, Xu XB, and Qu ZY were newly, but highly published authors in acupuncture on migraine research in recent years.

In the co-authorship analysis knowledge map, the blue cluster demonstrated that Linde $\mathrm{K}$ from Technical University Munich collaborated with Witt CM from the University of Zurich. The purple cluster suggested a collaboration between Allais et al from the Center for the Study of Natural and Physical Therapies and Airola $G$ from the University of Turin. The red cluster showed that Liang FR from Chengdu University of Traditional Chinese Medicine collaborated with Dong MK from Xinjin Hospital of Traditional Chinese Medicine and Liu ML from the Hunan University of Chinese Medicine. The green cluster indicated that Li B from Capital Medical University collaborated with Jing $\mathrm{XH}$ from China Academy of Chinese Medical Sciences. The light blue cluster indicated that Liu et al were from Beijing Hospital of Traditional Chinese Medicine. The light green cluster indicated that Zhao et al were from Chengdu University of Traditional Chinese Medicine.

In this study, numerous publications in high impact factor and cited journals showed the importance of acupuncture on 

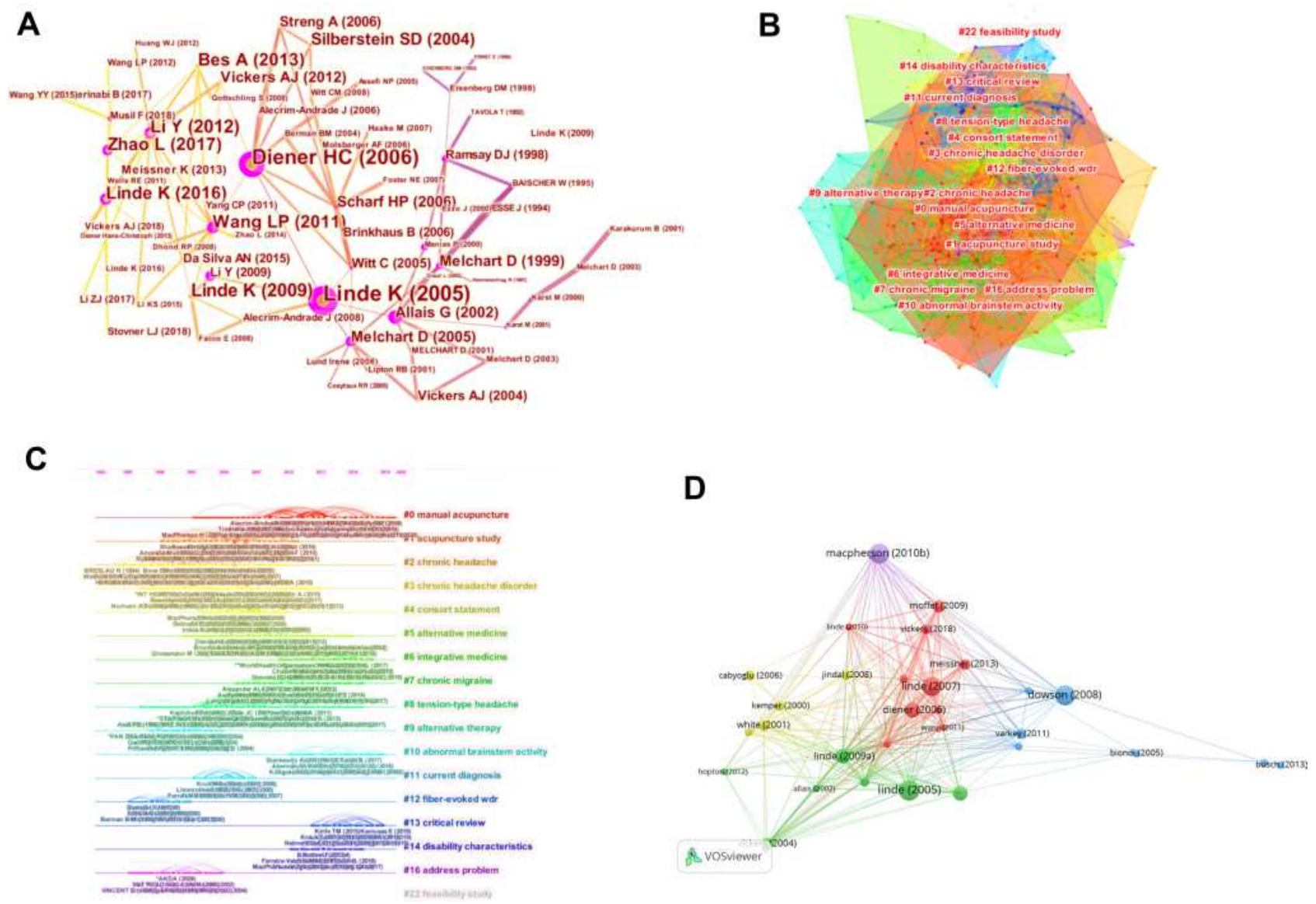

Figure 6 (A) The network of co-cited references related to acupuncture on migraine. (B) The cluster network of co-cited references related to acupuncture on migraine. (C). The timeline view network of co-cited references related to acupuncture on migraine. (D) The network visualization of cited references related to acupuncture on migraine.

migraine. The average impact factor (IF) of the top 10 journals was 2.3106. Interestingly, the journal of Cephalalgia ranked first in the number of publications, citation, co-citation, and IF (4.868), indicating that it played a key role in this field. Therefore, publications related to acupuncture on migraine in Cephalalgia are considered landmark studies. In addition, the journal of Medicine, World Journal of Acupuncture, and Frontiers in Neurology were newly published journals associated with acupuncture on migraine research. With respect to centrality, collaboration among countries, authors, and institutions was low, suggesting that cooperation is inadequate. ${ }^{30,31}$ Therefore,

Table 10 Top 10 Keywords Related to Acupuncture on Migraine

\begin{tabular}{|l|c|c|c|c|c|}
\hline Rank & Frequency & Keyword & Rank & Centrality & Keyword \\
\hline 1 & 283 & Migraine & 1 & 0.17 & Electroacupuncture \\
2 & 276 & Acupuncture & 2 & 0.17 & Tension type headache \\
3 & 132 & Headache & 3 & 0.14 & Double blind \\
4 & 115 & Pain & 4 & 0.13 & Efficacy \\
5 & 80 & Efficacy & 5 & 0.12 & Pain \\
6 & 79 & Randomized controlled trial & 6 & 0.12 & Placebo \\
7 & 72 & Placebo & 7 & 0.12 & Chinical trial \\
8 & 70 & Prophylaxi & 8 & 0.11 & Chronic pain \\
9 & 70 & Double blind & 9 & 0.11 & Prophylaxi \\
10 & 65 & Tension type headache & 10 & 0.10 & Analgesia \\
\hline
\end{tabular}


A

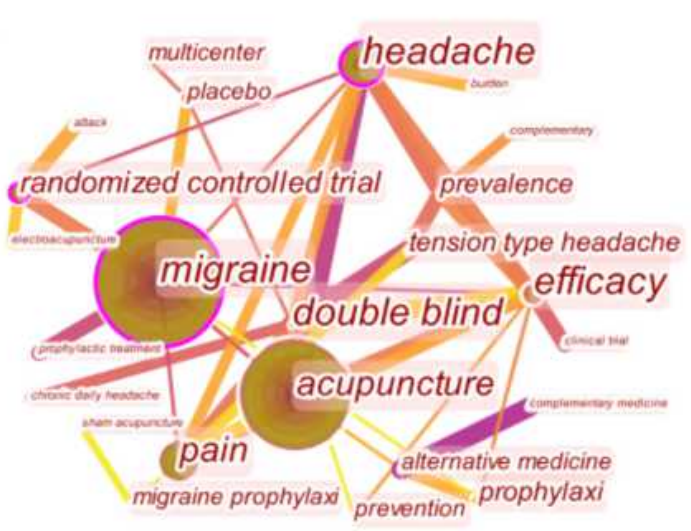

C

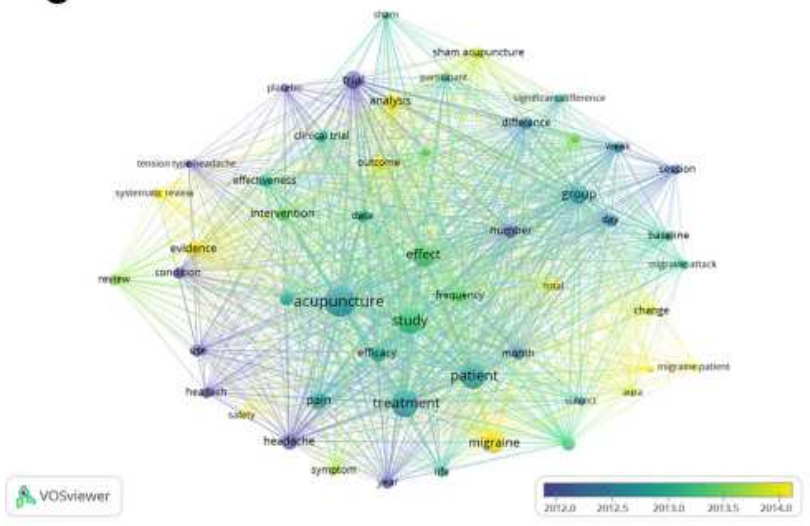

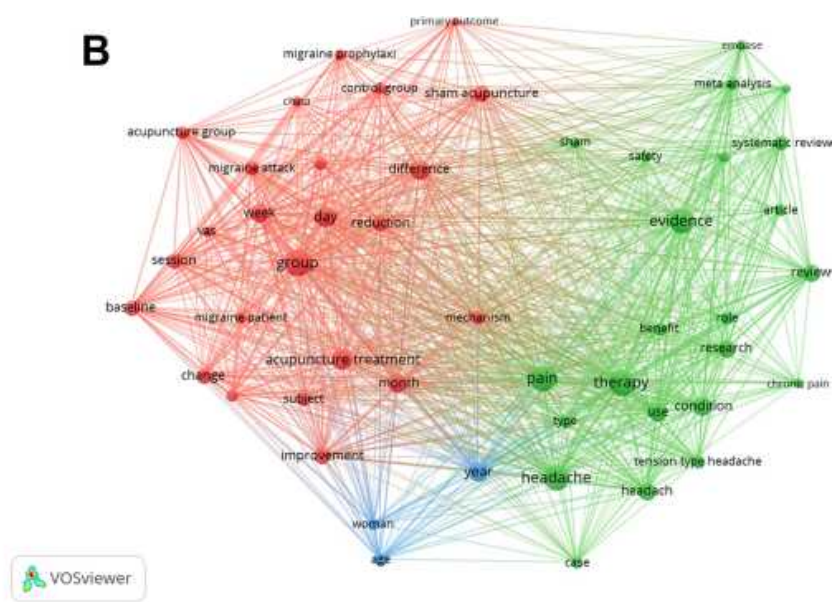

D

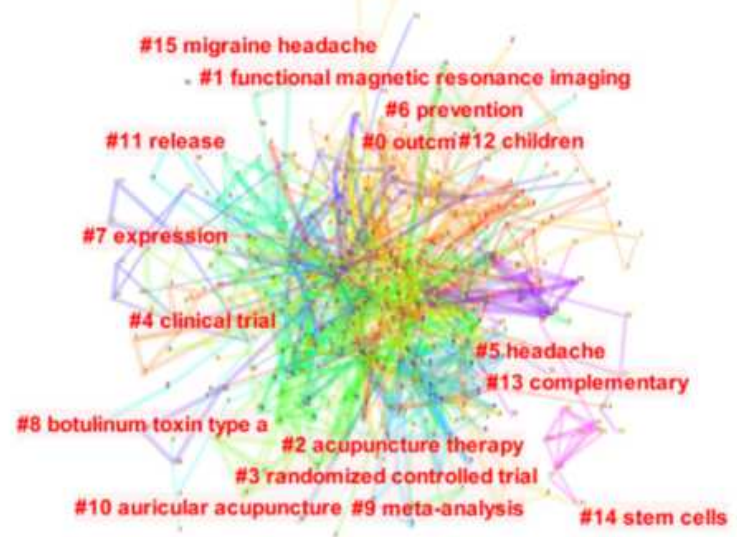

Figure 7 (A) Analysis of keyword related to acupuncture on migraine. (B) The visualization network of keywords related to acupuncture on migraine. (C) The overlay visualization network of keywords related to acupuncture on migraine. (D) The cluster network of keywords related to acupuncture on migraine.

researchers from different research areas and institutions should enhance cooperation for high-quality studies.

Analysis of the high co-citation frequency and centrality revealed adequate knowledge foundation related to acupuncture on migraine. ${ }^{30} \mathrm{~A}$ total of nine journals and two articles published by Cochrane Database of Systematic Reviews ${ }^{16,46}$ demonstrated the importance and influence of the journals in this field. Three articles were published by Linde $\mathrm{K}$ in $J A M A$ Journal of The American Medical Association ${ }^{3}$ and Cochrane Database of Systematic Reviews. ${ }^{16,46}$ The modularity $\mathrm{Q}(0.847)$ and the mean silhouette (0.9205) scores, ${ }^{29}$ obtained by CiteSpace. "Manual acupuncture" was the largest cluster, consisting of 114 members, and a silhouette value of 0.78 . The most active citer of this cluster was the review "Acupuncture for migraine prophylaxis" published by Linde et al. ${ }^{47}$ The second cluster "acupuncture study", had a silhouette value of 0.936 and a number of 78 . Furthermore, from the clusters of chronic headache, chronic headache disorder, consort statement, and alternative medicine, we could identify research directions in acupuncture for migraine, including the type of migraine, treatment and research, and acupuncture method.

\section{Emerging Research Trends Over the Past 20 Years}

Based on frequency, centrality, clusters and burst keywords, we identified hotspots and emerging research trends related to acupuncture on migraine. ${ }^{42}$

\section{The Most Common Type of Migraine}

Tension-type headache (TTH) is the most prevalent primary migraine. ${ }^{48}$ The keyword "TTH", emerged from 2008, with a strength of citation burst of 3.79 , demonstrating that TTH has been more popular than other types of migraine over the past two decades. A previously published review indicated 


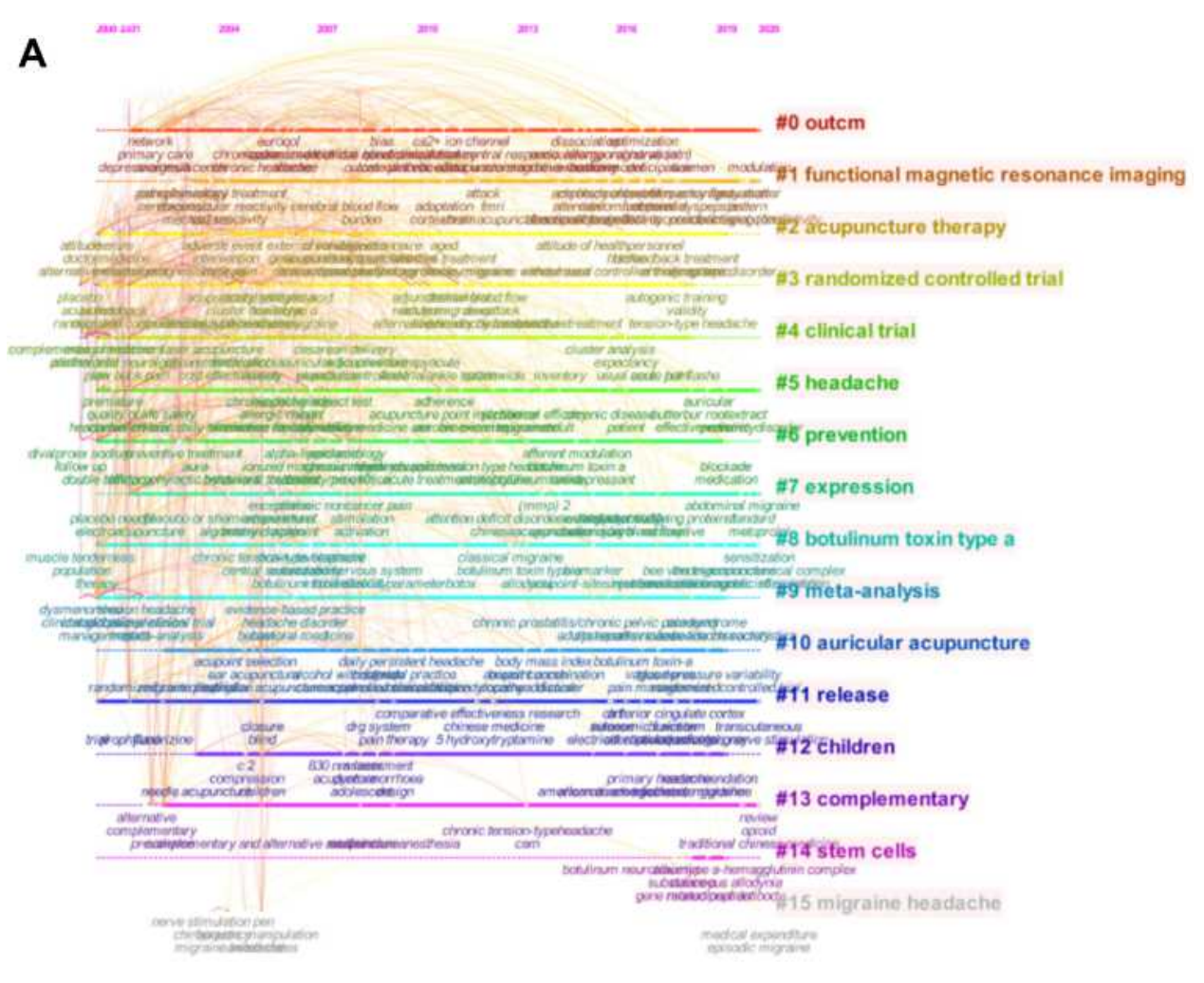

B

\section{Keywords Year Strength Begin End $2000-2020$}

$\begin{array}{lrrl}\text { complementary medicine } 2000 & 3.562000 & 2008 \\ \text { placebo } & 2000 & 52003 & 2010 \\ \text { needle acupuncture } & 2000 & 42003 & 2009 \\ \text { tension type headache } & 2000 & 3.522004 & 2010 \\ \text { multicenter } & 2000 & 3.392008 & 2012 \\ \text { management } & 2000 & 4.42016 & 2020 \\ \text { meta-analysis } & 2000 & 3.52017 & 2020 \\ \text { systematic review } & 2000 & 3.72018 & 2020 \\ \text { quality of life } & 2000 & 3.522018 & 2020\end{array}$

Figure 8 (A) The cluster timeline view network of keywords related to acupuncture on migraine. (B) The top 9 keywords with the strongest citation bursts related to acupuncture on migraine. The color represents different frequent keywords (red: frequent; green: infrequent).

that acupuncture could be a valuable option for TTH therapy. ${ }^{49}$ Moreover, clinical data from a study by Georgoudis G's suggests that TTH patients receiving acupuncture experienced significant improvement in psychosomatic pain, disability index, and QoL. ${ }^{50}$

\section{Research Method}

RCTs, multicenter, and double-blind studies are common research methods in acupuncture for migraine, providing high-quality clinical evidence. An RCT on acupuncture on migraine was published in JAMA Internal Medicine, with a high IF of 18.625. In this article, Zhao et al showed that the long-term reduction of migraine recurrence in the TA group was higher compared with the SA group and waitinglist control group. ${ }^{8}$ Besides, a randomized, double-blind, placebo-controlled trial, conducted by Gottschling et al found active acupuncture benefits compared with placebo acupuncture for headache patients. ${ }^{51}$ 
In acupuncture clinical research, it is difficult for researchers to conduct double-blind trials. ${ }^{52}$ Patient blinding can be achieved using sham acupuncture, but it is not easy to blind acupuncturist of manual treatments. Because the blinding of the observer and the analyst should be considered ideal for all studies. Although some attempts have been made using the novice and diagnostic blindness of acupuncturist, the quality of treatment may not be optimal and diagnosis may be irrelevant. ${ }^{52}$ Therefore, it is necessary to evaluate double-blind trials in future studies. Single-blinded trials are therefore popular in acupuncture on migraine. ${ }^{53}$

\section{Effect of Acupuncture on Migraine}

Studies report that approximately $25-38 \%$ of patients with migraine need preventive therapy. ${ }^{15,17}$ Acupuncture, as a method with no side effects, should be considered as a beneficial prophylactic treatment to reduce the frequency of migraine. ${ }^{49,54}$ Acute effect and long-term effect are the goals of acupuncture therapy on migraine, including pain relief and prevention of the frequency of migraine attacks in the future. ${ }^{55,56}$ Current research provides evidence for the potential role of acupuncture in the treatment and prophylaxis of migraine (acute migraine and TTH). ${ }^{20,57}$

Acupuncture treatment, a supplementary therapy, can reduce pain in patients with migraine. ${ }^{49}$ However, there are some divergent views on the effects of acupuncture among TA, SA, and placebo groups. ${ }^{58,59}$ These differences may be attributed to acupuncture method, acupoint prescription, and type of migraine..$^{3,8,60}$ Therefore, the effect of TA, SA, and placebo should be studied in future. In addition, The QoL of migraine patients is significantly decreased. $^{23}$ The recurrent and severe pain in patients with migraine can aggravate psychological pressure such as tension and anxiety. Acupuncture can result in reduced Visual Analog Scale scores and days of the attack, and improve QoL in migraine patients. ${ }^{61}$

\section{Evaluation}

Meta-analysis and systematic reviews evaluate the efficacy of acupuncture in terms of pain, frequency of migraine attacks, anxiety and depression, and QoL, ${ }^{62}$ and compare with no treatment or other forms of therapy (blank control, usual care, waiting-list control, acupoint catgut embedding treatment, Western medication, SA, and placebo) in patients with migraine. ${ }^{62}$ However, results are limited due to the various methodological heterogeneity in the quality of the studies. ${ }^{11,61}$ Therefore, it is necessary to perform a high-quality meta-analysis to determine the effect of acupuncture in the future.

There were some limitations in this study. First, we mainly concentrated on quantitative analysis and focused less on qualitative analysis. Second, only articles recorded in WoS were analyzed; therefore, it is necessary to perform further analysis in other databases such as PubMed, Scopus, China National Knowledge Infrastructure, Wan Fang, and Wei Pu. However, WoS is the most commonly used database for scientometrics. ${ }^{32}$

\section{Conclusion}

Using CiteSpace and VOSviewer, a bibliometric analysis of acupuncture therapy on migraine over the past two decades is performed. The top five most prolific countries reporting high acupuncture on migraine research are the USA, China, Germany, England, and Italy. The most productive institutions in terms of publications in this field are Chengdu University of Traditional Chinese Medicine, Harvard University, and Technical University Munich. The most active authors are Liang FR, Linde K, and Li Y. Cephalalgia, Headache, and Acupuncture In Medicine are the most productive journals in this field. TTH and chronic migraine are the main types of migraine in acupuncture. The most common acupuncture methods applied to migraine are manual acupuncture and electroacupuncture. Moreover, RCT, multicenter, doubleblind, and functional magnetic resonance imaging studies, are the current main research methods used to study acupuncture on migraine. Acupuncture can affect migraine as the role of prophylactic, and alleviate QoL, and pain. Meta-analysis and systematic reviews have been widely used to evaluate the efficacy of acupuncture for migraine.

In summary, this study is the first bibliometric analysis to investigate the current status and emerging trends related to acupuncture on migraine using CiteSpace and VOSviewer over the last 20 years. The trends demonstrated of acupuncture therapy on migraine may help researchers explore new directions for future research in this field.

\section{Abbreviations}

QoL, Quality of life; RCT, randomized controlled trials; TA, true acupuncture; SA, sham acupuncture; WoS, Web of Science; IF, Impact factor; TTH, Tension-type headache.

\section{Data Sharing Statement}

The raw data used in this article can be obtained from the Web of Science (WoS) database. 


\section{Acknowledgment}

The authors would like to express their appreciation to Professor CM Chen and van EckNJ, who invented CiteSpace and VOSviewer.

\section{Author Contributions}

All authors made a significant contribution to the work reported, whether in the conception, study design, execution, acquisition of data, analysis and interpretation, or in drafting, revising or critically reviewing the article. All authors approved the final version of this manuscript submitted for publication, agreed on the journal to which the article has been submitted, and to be accountable for all aspects of the work.

\section{Funding}

This study was supported by the National Administration of Traditional Chinese Medicine: 2019 Project BEBPCTCM (No.2019XZZX-ZJ008), Science and Technology Department of Jiangsu Province Project (No. BE2020788), Social Development Special Project of Jiangsu Science and Technology Department (BE2020788) and the Leading Talents of Traditional Chinese Medicine in Jiangsu Province (SLJ0206).

\section{Disclosure}

The authors declare no potential conflicts of interest in this research.

\section{References}

1. Diener HC, Kronfeld K, Boewing G, et al. Efficacy of acupuncture for the prophylaxis of migraine: a multicentre randomised controlled clinical trial. Lancet Neurol. 2006;5(4):310-316. doi:10.1016/S14744422(06)70382-9

2. Charles JA, Rapoport AM. The American Headache Society's position statement on integrating new migraine treatments into clinical practice comments. Headache. 2019;59(4):629. doi:10.1111/head.13496

3. Linde K, Streng A, Jürgens S, et al. Acupuncture for patients with migraine: a randomized controlled trial. JAMA. 2005;293 (17):2118-2125. doi:10.1001/jama.293.17.2118

4. Wells RE, O'Connell N, Pierce CR, et al. Effectiveness of mindfulness meditation vs headache education for adults with migraine: a randomized clinical trial. JAMA Intern Med. 2021;181(3):317-328. doi:10.1001/jamainternmed.2020.7090

5. GBD 2017 Disease and Injury Incidence and Prevalence Collaborators. Global, regional, and national incidence, prevalence, and years lived with disability for 354 diseases and injuries for 195 countries and territories, 1990-2017: a systematic analysis for the Global Burden of Disease Study 2017. Lancet. 2018;392 (10159):1789-1858.

6. Feigin VL, Abajobir AA, Abate $\mathrm{KH}$, et al. Global, regional, and national burden of neurological disorders during 1990-2015: a systematic analysis for the Global Burden of Disease Study 2015. Lancet Neurol. 2017;16(11):877-897. doi:10.1016/S1474-4422(17) 30299-5
7. Feigin VL, Nichols E, Alam T. Global, regional, and national burden of neurological disorders, 1990-2016: a systematic analysis for the Global Burden of Disease Study 2016. Lancet Neurol. 2019;18 (5):459-480. doi:10.1016/S1474-4422(18)30499-X

8. Zhao L, Chen J, Li Y, et al. The long-term effect of acupuncture for migraine prophylaxis: a randomized clinical trial. JAMA Intern Med. 2017;177(4):508-515. doi:10.1001/jamainternmed.2016.9378

9. Burch RC, Loder S, Loder E, Smitherman TA. The prevalence and burden of migraine and severe headache in the United States: updated statistics from government health surveillance studies. Headache. 2015;55(1):21-34. doi:10.1111/head.12482

10. Wang SJ. Epidemiology of migraine and other types of headache in Asia. Curr Neurol Neurosci Rep. 2003;3(2):104-108. doi:10.1007/ s11910-003-0060-7

11. Xu J, Zhang FQ, Pei J, Ji J. Acupuncture for migraine without aura: a systematic review and meta-analysis. $J$ Integr Med. 2018;16 (5):312-321. doi:10.1016/j.joim.2018.06.002

12. Marmura MJ, Silberstein SD, Schwedt TJ. The acute treatment of migraine in adults: the American headache society evidence assessment of migraine pharmacotherapies. Headache. 2015;55(1):3-20. doi: 10.1111/head.12499

13. Evers S, Afra J, Frese A, et al. EFNS guideline on the drug treatment of migraine-revised report of an EFNS task force. Eur J Neurol. 2009;16(9):968-981. doi:10.1111/j.1468-1331.2009.02748.x

14. Dodick DW, Silberstein SD. Migraine prevention. Pract Neurol. 2007;7(6):383-393. doi:10.1136/jnnp.2007.134023

15. Pringsheim T, Davenport W, Mackie G, et al. Canadian headache society guideline for migraine prophylaxis. Can J Neurol Sci. 2012;39(2 Suppl 2):S1-S59.

16. Linde K, Allais G, Brinkhaus B, Manheimer E, Vickers A, White AR. Acupuncture for migraine prophylaxis. Cochrane Database Syst Rev. 2009;1:D1218.

17. Tfelt-Hansen PC. Evidence-based guideline update: pharmacologic treatment for episodic migraine prevention in adults: report of the quality standards subcommittee of the American Academy of Neurology and the American Headache Society. Neurology. 2013;80 (9):869-870. doi:10.1212/01.wnl.0000427909.23467.39

18. Linde M, Mulleners WM, Chronicle EP, McCrory DC. Valproate (valproic acid or sodium valproate or a combination of the two) for the prophylaxis of episodic migraine in adults. Cochrane Database Syst Rev. 2013;6:D10611.

19. Wang LP, Zhang XZ, Guo J, et al. Efficacy of acupuncture for migraine prophylaxis: a single-blinded, double-dummy, randomized controlled trial. Pain. 2011;152(8):1864-1871. doi:10.1016/j. pain.2011.04.006

20. Coeytaux RR, Befus D. Role of acupuncture in the treatment or prevention of migraine, tension-type headache, or chronic headache disorders. Headache. 2016;56(7):1238-1240. doi:10.1111/ head. 12857

21. Urits I, Patel M, Putz ME, et al. Acupuncture and its role in the treatment of migraine headaches. Neurol Ther. 2020;9(2):375-394. doi:10.1007/s40120-020-00216-1

22. Xu S, Yu L, Luo X, et al. Manual acupuncture versus sham acupuncture and usual care for prophylaxis of episodic migraine without aura: multicentre, randomised clinical trial. BMJ. 2020;368:m697. doi:10.1136/bmj.m697

23. Cayir Y, Ozdemir G, Celik M, et al. Acupuncture decreases matrix metalloproteinase-2 activity in patients with migraine. Acupunct Med. 2014;32(5):376-380. doi:10.1136/acupmed-2014-010612

24. Liao CC, Liao KR, Lin CL, Li JM. Long-term effect of acupuncture on the medical expenditure and risk of depression and anxiety in migraine patients: a Retrospective Cohort Study. Front Neurol. 2020;11:321. doi:10.3389/fneur.2020.00321

25. Zhang XT, Li XY, Zhao C, et al. An overview of systematic reviews of randomized controlled trials on acupuncture treating migraine. Pain Res Manag. 2019;2019:5930627. doi:10.1155/2019/5930627 
26. Li Z, Lan L, Zeng F, et al. The altered right frontoparietal network functional connectivity in migraine and the modulation effect of treatment. Cephalalgia. 2017;37(2):161-176. doi:10.1177/ 0333102416641665

27. Li Z, Zeng F, Yin T, et al. Acupuncture modulates the abnormal brainstem activity in migraine without aura patients. Neuroimage Clin. 2017;15:367-375. doi:10.1016/j.nicl.2017.05.013

28. Qin Y, Zhang Q, Liu Y. Analysis of knowledge bases and research focuses of cerebral ischemia-reperfusion from the perspective of mapping knowledge domain. Brain Res Bull. 2020;156:15-24. doi:10.1016/j.brainresbull.2019.12.004

29. Pei W, Peng R, Gu Y, Zhou X, Ruan J. Research trends of acupuncture therapy on insomnia in two decades (from 1999 to 2018): abibliometric analysis. BMC Complement Altern Med. 2019;19 (1):225. doi:10.1186/s12906-019-2606-5

30. Li R, Sun J, Hu H, et al. Research trends of acupuncture therapy on knee osteoarthritis from 2010 to 2019: a bibliometric analysis. J Pain Res. 2020;13:1901-1913. doi:10.2147/JPR.S258739

31. Liang YD, Li Y, Zhao J, Wang XY, Zhu HZ, Chen XH. Study of acupuncture for low back pain in recent 20 years: a bibliometric analysis via CiteSpace. J Pain Res. 2017;10:951-964. doi:10.2147/ JPR.S132808

32. Guo J, Pei L, Chen L, et al. Research trends of acupuncture therapy on cancer over the past two decades: a bibliometric analysis. Integr Cancer Ther. 2020;19:1872177874. doi:10.1177/1534735420959442

33. Yao L, Hui L, Yang Z, Chen X, Xiao A. Freshwater microplastics pollution: detecting and visualizing emerging trends based on citespace II. Chemosphere. 2020;245:125627. doi:10.1016/j. chemosphere.2019.125627

34. Chen C, Leydesdorff L. Patterns of connections and movements in dual-map overlays: a new method of publication portfolio analysis J Assoc Inf Sci Tech. 2013;65(2):334-351. doi:10.1002/asi.22968

35. van Eck NJ, Waltman L. Software survey: vOSviewer, a computer program for bibliometric mapping. Scientometrics. 2010;84 (2):523-538. doi:10.1007/s11192-009-0146-3

36. van Eck NJ, Waltman L. Citation-based clustering of publications using CitNetExplorer and VOSviewer. Scientometrics. 2017;111 (2): 1053-1070. doi:10.1007/s11192-017-2300-7

37. Chen $\mathrm{C}$ The centrality of pivotal points in the evolution of scientific networks. 2005 International Conference on Intelligent User Interfaces. 2005:98-105.

38. Chen C. CiteSpace II: detecting and visualizing emerging trends and transient patterns in scientific literature. J Am Soc Inf Sci Technol. 2006;57(3):359-377. doi:10.1002/asi.20317

39. Paul S, Kokossis A, Gage H, et al. A semantically enabled formalism for the knowledge management of parkinson's disease. Med Inform Internet Med. 2006;31(2):101-120. doi:10.1080/14639230500299220

40. MacPherson H, Altman DG, Hammerschlag R, et al. Revised STandards for Reporting Interventions in Clinical Trials of Acupuncture (STRICTA): extending the CONSORT statement. PLoS Med. 2010;7(6):e1000261. doi:10.1371/journal.pmed.1000261

41. Jena S, Witt CM, Brinkhaus B, Wegscheider K, Willich SN. Acupuncture in patients with headache. Cephalalgia. 2008;28 (9):969-979. doi:10.1111/j.1468-2982.2008.01640.x

42. Zheng K, Wang X. Publications on the association between cognitive function and pain from 2000 to 2018: a bibliometric analysis using CiteSpace. Med Sci Monit. 2019;25:8940-8951. doi:10.12659/ MSM.917742

43. Kristoffersen ES, Grande RB, Aaseth K, Lundqvist C, Russell MB. Management of primary chronic headache in the general population: the Akershus study of chronic headache. J Headache Pain. 2012;13 (2):113-120. doi:10.1007/s10194-011-0391-8

44. Millstine D, Chen CY, Bauer B. Complementary and integrative medicine in the management of headache. BMJ. 2017;357:j1805. doi:10.1136/bmj.j1805
45. Li Z, Zhou J, Lan L, et al. Concurrent brain structural and functional alterations in patients with migraine without aura: an fMRI study. $J$ Headache Pain. 2020;21(1):141. doi:10.1186/s10194-020-01203-5

46. Linde K, Allais G, Brinkhaus B, et al. Acupuncture for the prevention of episodic migraine. Cochrane Database Syst Rev. 2016;6:D1218.

47. Linde K, Allais G, Brinkhaus B, Manheimer E, Vickers A, White AR. Acupuncture for Migraine Prophylaxis. John Wiley \& Sons, Ltd; 2009.

48. Sahler K. Epidemiology and cultural differences in tension-type headache. Curr Pain Headache Rep. 2012;16(6):525-532. doi:10.1007/s11916-012-0296-5

49. Linde K, Allais G, Brinkhaus B, et al. Acupuncture for the prevention of tension-type headache. Cochrane Database Syst Rev. 2016;4: D7587. doi:10.1002/14651858.CD007587.pub2

50. Georgoudis G, Felah B, Nikolaidis PT, et al. The effect of physiotherapy and acupuncture on psychocognitive, somatic, quality of life, and disability characteristics in TTH patients. $J$ Pain Res. 2018;11:2527-2535. doi:10.2147/JPR.S178110

51. Gottschling S, Meyer S, Gribova I, et al. Laser acupuncture in children with headache: a double-blind, randomized, bicenter, placebo-controlled trial. Pain. 2008;137(2):405-412. doi:10.1016/j. pain.2007.10.004

52. Day SJ, Altman DG. Statistics notes: blinding in clinical trials and other studies. BMJ. 2000;321(7259):504. doi:10.1136/ bmj.321.7259.504

53. White AR, Filshie J, Cummings TM. Clinical trials of acupuncture: consensus recommendations for optimal treatment, sham controls and blinding. Complement Ther Med. 2001;9(4):237-245. doi:10.1054/ ctim.2001.0489

54. Govind N. Acupuncture for the prevention of episodic migraine. Res Nurs Health. 2019;42(1):87-88. doi:10.1002/nur.21933

55. Li Y, Liang F, Yang X, et al. Acupuncture for treating acute attacks of migraine: a randomized controlled trial. Headache. 2009;49 (6):805-816. doi:10.1111/j.1526-4610.2009.01424.x

56. Wang LP, Zhang XZ, Guo J, et al. Efficacy of acupuncture for acute migraine attack: a multicenter single blinded, randomized controlled trial. Pain Med. 2012;13(5):623-630. doi:10.1111/j.15264637.2012.01376.x

57. Allais G, Sinigaglia S, Airola G, et al. Ear acupuncture in the prophylactic treatment of chronic migraine. Neurol Sci. 2019;40 (Suppl 1):211-212. doi:10.1007/s10072-019-03800-y

58. Wells RE, Beuthin J, Granetzke L. Complementary and integrative medicine for episodic migraine: an update of evidence from the last 3 years. Curr Pain Headache Rep. 2019;23(2):10. doi:10.1007/s11916019-0750-8

59. Farahmand S, Shafazand S, Alinia E, Bagheri-Hariri S, Baratloo A. Pain management using acupuncture method in migraine headache patients; a single blinded randomized clinical trial. Anesth Pain Med. 2018;8(6):e81688. doi:10.5812/aapm.81688

60. Foroughipour M, Golchian AR, Kalhor M, Akhlaghi S, Farzadfard MT, Azizi H. A sham-controlled trial of acupuncture as an adjunct in migraine prophylaxis. Acupunct Med. 2014;32 (1):12-16. doi:10.1136/acupmed-2013-010362

61. Jiang Y, Bai P, Chen H, et al. The effect of acupuncture on the quality of life in patients with migraine: a systematic review and meta-analysis. Front Pharmacol. 2018;9:1190. doi:10.3389/ fphar.2018.01190

62. Li X, Dai Q, Shi Z, et al. Clinical efficacy and safety of electroacupuncture in migraine treatment: a systematic review and network meta-analysis. Am J Chin Med. 2019;47(8):1755-1780. doi:10.1142/ S0192415X19500897 
Journal of Pain Research

Dovepress

\section{Publish your work in this journal}

The Journal of Pain Research is an international, peer reviewed, open access, online journal that welcomes laboratory and clinical findings in the fields of pain research and the prevention and management of pain. Original research, reviews, symposium reports, hypothesis formation and commentaries are all considered for publication. The manuscript management system is completely online and includes a very quick and fair peer-review system, which is all easy to use. Visit http:// www.dovepress.com/testimonials.php to read real quotes from published authors.

Submit your manuscript here: https://www.dovepress.com/journal-of-pain-research-journal 